\title{
New Data on the Genetics of Parkinson's Disease
}

\author{
ANDRE BARBEAU and EMMANUELLE POURCHER
}

\begin{abstract}
SUMMARY: We investigated the clinical and metabolic characteristics of Parkinsonian patients whose illness started before the age of 40 . A pilot study of 32 of our own such cases revealed the existence of 3 subgroups: 1.Post-Encephalitic, 2. Onset and course with predominant tremor, 3. Onset and course with akinesia and rigidity. In this early onset group of patients, there was a $46 \%$ incidence of familial cases (as opposed to $10-15 \%$ in the general Parkinson population). The cases with tremor onset had a high prevalence of essential tremor in their families, while those with an akinetorigid onset had a high familial incidence of other cases of Parkinson's Disease. Familial grey hair, hypertension, diabetes and thyroidopathies appeared to be in higher than expected frequency.
\end{abstract}

RÉSUMÉ: Nous avons étudié les caractéristiques cliniques et métaboliques de patients parkinsoniens dont la maladie a débuté avant l'âge de 40 ans. Une étude pilote chez 32 de nos propres patients révéla l'existence de 3 sous-groupes: 1. post-encéphalitique; 2 début et évolution $\dot{a}$ prédominance tremblante; 3. début et évolution à prédominance akinéto-rigide. Chez les patients de ce groupe à début hâtif, l'incidence de cas familiaux était de $46 \%$ (comparée à 10-15\% dans la population de Parkinsoniens prise dans son ensemble).

Il existe une incidence élevée de tremblement essentiel dans les familles de patients à début tremblant, alors que l'incidence de Parkinson typique familial est plus élevée chez les malades à début akinéto-rigide. Nous avons également mis en évidence une incidence élevée d'hypertension, de diabète, de cheveux gris hâtifs et surtout de thyroïdopathies chez cerlains de ces patients.

Ces tendances observées chez nos propres patients furent confirmées par l'étude

From the Department of Neurobiology, Clinical Research Institute of Montreal and University of Montreal.

Based on the Cotzias Lecture given at the 12th World Congress of Neurology, Kyoto, Japan September 23, 1981.

Reprint Requests to: Prof. André Barbeau, Clinical Research Institute of Montreal, 110 West Pine Ave, Montreal, Quebec, Canada H2W 1 R7.
These trends were confirmed in a larger series of 135 cases of early onset Parkinson obtained through a mail survey. When the same clinical material was analysed for the familial cases only, two new genetic subgroups emerged: 1) a familial metabolic akineto-rigid syndrome (with hypertension, familial diabetes, hypothyroidism and a more severe course) and, 2) a familial essential tremor-related Parkinsonian syndrome (with familial grey hair trait and hyperthyroidism). These new genetic syndromes along with the recently described "Familial juvenile Parkinsonism" require many further prospectives metabolic and clinical investigations for full characterization, but confirm our hypothesis that "idiopathic" Parkinson's disease is not a single homogeneous entity.

de 135 parkinsoniens à début hâtif (avant âge 40) obtenus par correspondance avec des neurologues américains. Lorsque ce matériel clinique a été analysé, il est apparu que les cas familiaux pouvaient se diviser en deux nouveaux sous-groupes génétiques: 1) un syndrome familial akinetorigide métabolique (avec hypertension, diabète, hypothyroiddie et une évolution plus sévère) et 2) un syndrome parkinsonien familial "relié au tremblement essentiel" (avec cheveux gris hâtifs fréquents, et hyperthyroïdie). Ces nouveaux syndromes génétiques, additionnées à la forme de Parkinson juvénile familial récemment décrite par les auteurs japonais, nécessitent une investigation métabolique et clinique plus poussée, et prospective, avant d'épouser une nosologie définitive. Leur existence, cependant, confirme notre hypothèse selon laquelle la maladie de Parkinson dite "idiopathique" n'est pas en fait une entité clinique homogène.

\section{INTRODUCTION}

Ever since James Parkinson described "Paralysis Agitans" in 1817, the question of the possible genetic origin of the disease has been raised. Most textbooks answer directly with a resounding "no", but the literature keeps the problem alive with occasional positive surveys. It is evident, as most investigations into etiologic hypotheses fail to turn up definitive answers, that we should reopen the subject and take a second look at the old studies and at ongoing research.

Kessler (1978) has recently reviewed the large number of earlier individual studies. We will not attempt to do this in the present paper. Suffice it to say that the percentage of familial incidence in the various series oscillates between $2.5 \%$ and $94.5 \%$, probably depending on ascertainment and definition of "Parkinsonism", with most results situated between $10 \%$ and $15 \%$. For example, Duvoisin et al (1969) have recalculated the old data of Mjönes (1949). Whereas the former author had reported an incidence of $41 \%$, once cases of pure tremor and other possible diagnosis were excluded, the new figures become $2.8 \%$ in parents and $3.4 \%$ in siblings, (or $7 \%$ of first degree relatives). In his own series of 145 patients, Duvoisin (1969) observed 3 secondary cases, while only one was seen among 145 spouses and relatives. The author concludes that no genetic component is involved and that the results are due to chance occurence only. Recently Ward, Duvoisin and collaborators (1981) reported on twins in Parkinson's Disease. A maximum of 2 concordant pairs were found among the 17 monozygotic pairs. None were seen from 14 dizygotic pairs. However, 7 more cases of Parkinsonism were found in immediate relatives of the monozygotic twins. Again increased heritability must be considered possible.

In a very thoughtful study, $K$ ando et al (1973) reanalyzed the data from 
Minnesota and from Sweden and concluded that it was impossible to accept the "modified" autosomal dominance suggested by Mjönes (1949) and others. They proposed, instead, that the high heritability (circa $80 \%$ ), was due to a multifactorial etiology (where genetic and environmental factors interplay). A similar conclusion was reached by Martin et al (1973) from an independent study of their own clinical material.

Such a mode of transmission would be compatible with the observed increase in Parkinsonism-like complications from neuroleptics in certain population sub-groups and the fact that Parkinson's disease is more frequent among relatives of patients responding to these neuroleptics with Parkinsonism (Ayd, 1961). Thus, $2.5 \%$ of 486 relatives of such propositi had Parkinson's disease as compared to only $0.6 \%$ in 483 relatives of control subjects (Myriantropoulos et al, 1969).

In 1973, Barbeau (unpublished study) carried out a survey of 300 consecutive cases of Parkinson's disease. Among 1630 first degree relatives on whom a history could be obtained, he found 126 other cases of probable Parkinson's disease (or tremor). In a control population of 300 age-matched neighbors (1580 traceable first degree relatives), he found 38 cases of possible Parkinson's disease (PD) among relatives and 5 cases of definite PD in the neighbors themselves. Thus, roughly $13 \%$ of PD patients and $5 \%$ of controls have one or more first degree relative with an extrapyramidal syndrome resembling Parkinson's disease. This 2-3 times higher incidence would, at first glance, appear to be a significant finding, but calculation of the expected rate is based on data not yet fully corroborated. Thus, most authors state that the prevalence of $P D$ is $1 / 1000$ in the general population. In subjects aged 40 and over, the figures given are $1 / 200$; over age 60 the prevalence is said to be $1 / 100$. Recently, however, Kurland (personal communication) stated that for individuals living out their full life (average of 76 and 72 in women and men respectively) the expected prevalence rate should be $1 / 40$. At such a rate, if the probant in a study has definite PD, we calculate that another instance of PD among first degree relatives should be found in $15 \%$ of families by chance alone, if the family size is 7 .

Thus the question of the existence of genetic factors, including the polygenic model, is still unsettled because the data base necessary for calculations and comparisons is lacking. Since all authors have to date utilized the same overall methodology in case finding, it is not surprising that almost all come to the same conclusion, i.e. that a first degree relative will be found to have PD, in approximately $10-15 \%$ of cases, a figure that appears to reflect mainly a statistical artefact. However, one could reasonably ask whether this artefact may not be caused by a wrong assumption: that all so-called "Idiopathic Parkinson's disease" cases are identical. If this is not so, and if there exists one or more sub-groups of patients within that large "idiopathic" group that are clearly hereditary, it is not impossible that the $10-15 \%$ figures reflect the presence of those sub-groups in every population yet studied. Expressed differently the question could be: Is "Idiopathic Parkinson's disease" a single entity? The present paper will offer new evidence on these points.

\section{ARE THERE MANY FORMS OF IDIOPATHIC PARKINSON'S DISEASE?}

The problem of the non homogeneity of idiopathic Parkinson's Disease has been raised before, and by a number of authors, but unfortunately the results have been a wide variety of classifications. For example Mjönes in his 1949 monograph described one group with early onset (below age 40) and with a generally more severe course; and another group of later onset and with a more benign course. Surprisingly, Birkmayer et al (1979) delineated two types with exactly opposite characteristics: benign type, with earlier onset, more frequent in males and of longer duration; malignant type with later onset, more severe disease and a shorter course. Looking at studies of the intellectual deficit present in Parkinson's disease, Mortimer et al (1981) were more impressed by the clinical presentation: a bradykinetic form with specific deficits in visual-spatial func- tions, and a tremor form, with no such deficits. Finally, last year, Yokochi and Narabayashi (1981) reported on what they called "juvenile Parkinsonism". Interestingly for most of us, they defined "juvenile" onset below age 39 . The frequency of such cases in Japan was between $10 \%$ and $18 \%$ of all Parkinsonians, a figure entirely similar to our own experience. They noted in this group a familial incidence of $42.5 \%$. Because in our own clinic we had noted very similar patterns, we decided to take a closer look at our patients with onset of the disease below the age of 40. An added advantage to this approach is that it avoids most complications from arteriosclerosis or premature aging.

\section{PERSONAL SERIES OF EARLY ONSET PARKINSONISM}

At the time we started this study, there were 342 patients with $\mathrm{Par}$ kinson's Disease being followed actively and regularly (every 2 months), in our clinic, with a total registry of 643 Parkinsonian patients (the others are mainly seen on consultation, or once a year). 32 patients $(9.4 \%)$ had a history of having started this disease before their 40th birthday. Each of these patients was studied with a detailed family history, physical, metabolic and neurological examination. Special attention was paid to type of occupation, occupational hazards, exposure to toxins or to drugs, place of birth or of employment, work history, diseases prevalent in the relatives. Care was taken to clearly establish if "affected" relatives had Parkinson's disease or one of the many tremor syndromes, a precaution not always observed in previous series, including our own.

Of the 32 index cases, 3 had an atypical striatal syndrome; one was clearly post-encephalitic, 18 presented with the full triad of rigidity, akinesia and tremor, while 2 had a familial akineto-rigid syndrome and 8 a familial tremor syndrome. The familial incidence in the sub-group of idiopathic Parkinson's disease of early onset was $36 \%$, a figure almost the same as that of Yokochi and Narabayashi (1981). We thus confirm that previous observation made on a total of 40 cases. Similarly, it was shown that this group 
of patients responded well to Levodopa $(58 \%$ had a durable and useful effect, while $23 \%$ had no effect), but that dyskinesia (84\%) and on/off effects (58\%) were quite frequent, both complications occuring early $(42 \%$ and $35 \%$ respectively before two years of treatment).

Four observations of possible metabolic importance were also made in this group of patients: 3 of the 32 subjects (9.4\%) had evidence of macrocytic anemia. $18 \%$ had had abnormal thyroid functions (similar findings in $14 \%$ of their families); $25 \%$ were clinically diabetics, (diabetes present in $78 \%$ of their families) and $32 \%$ were hypertensive (hypertension present in $51 \%$ of the proband families). These results indicate important leads into possible causative factors for Parkinson's disease, particularly when the relatively young age of onset is taken into account.

Many authors had noted a decreased prevalence of cigarette smoking in Parkinson's disease, a fact consonant with the very low incidence of lung cancer in this group (Barbeau and Joly, 1963; Baumann et al, 1980). We confirm this tendency, since only $35 \%$ of our patients, in this below 40-onset age group, have ever smoked.

Thus, this initial survey of our own cases confirms the impression of Yokochi and Narabayashi (1981) that this group of patients is of special interest and has a high incidence of familial cases. We further add that they smoke less than the control population, and that they have a high incidence of diabetes, of macrocytic anemia and of thyroidopathy.

Unfortunately, since we found only 10 cases of "familial" Parkinsonism, the numbers were too small to carry out proper genetic analysis. In order to do this, we needed much larger groups, not immediately available, thus, the need for the following survey:

\section{SURVEY OF A LARGE CORRESPONDENCE SERIES}

Through the unfailing cooperation of the United Parkinson Foundation and the Fondation Parkinson du Québec, we advertised our need for such patients. In answer to this solicitation, we received 315 letters of enquiry. Detailed questionnaires were sent to each respondent. A total of 203 questionnaires were filled-out, but 25 in an incomplete fashion. Communication was then made with the treating physician and afterwards with the consulting neurologist. Detailed examination notes were obtained. In 23 instances the diagnosis of Parkinson's Disease was either "atypical", or could not be confirmed. Thus we were able to retain 155 cases of fully-confirmed Parkinsonism with onset before the age of 40 . Further correspondence was then carried out with the treating physicians of possibly affected relatives after obtaining consent. Lack of cooperation or doubtful answers further eliminated 20 cases from our lists. Thus, we retained for study a total of 135 Index Cases of early-onset Parkinsonism. All were of white extraction.

To obtain a control group, we surveyed the family and relatives of 30 subjects with diseases other than Parkinson's syndrome; these subjects were matched for age and sex with the first 30 index cases. A similar process of correspondence was carried out and family histories obtained with confirmed diagnosis.

Eventually, the 135 index cases were classified into 3 patient sub-groups and one control group according to the mode of onset. These were:

\section{Sub-Group I: POST-ENCE- PHALITIC}

(N: 11, 64\% males, mean age 57.1 yrs; mean age of onset $29.5 \mathrm{yrs}$; mean duration of illness by 1980 : 26.2 years).

\section{Sub-Group II: ONSET WITH TREMOR}

(N: $64,63 \%$ males, mean age 53.0 yrs; mean age of onset $34.1 \mathrm{yrs}$; mean duration of illness by 1980 : 17.4 years)

3. Sub-Group III: ONSET WITH RIGIDITY AND/OR AKINESIA

(N: $60,53 \%$ males; mean age 51.8 yrs; mean age of onset $32.6 \mathrm{yrs}$; mean duration of illness by 1980: 20.1 years)
4. CONTROL GROUP: NO PARKINSON'S DISEASE NOR ESSENTIAL TREMOR IN SUBJECTS

(N: $30,50 \%$ males; mean age 52.3 years).

As expected sub-group 3 was more severely affected than sub-group 2 (27\% vs $8 \%$ of subjects had reached stage 3 in a scale from 0-3). The family history of tremor or Parkinsonism was significantly more positive in all subgroups of patients (control: 3\%; S.G.I.: 45\%; S.G.II: 55\%; S.G.III: $35 \%$ ) being highest in those patients whose disease started with tremor. $46 \%$ of all patients (N: 135) with early onset Parkinson's disease thus had a positive family history of extrapyramidal signs. If first degree relatives only are considered, the percentages are still higher than in the control group.

Thus $0 \%$ of control subjects had first degree relatives with tremor or Parkinsonism. Tremor as the main symptom in relatives was seen in $20 \%$ of S.G.II and $8 \%$ of S.G.III patients; while Parkinson's disease (confirmed) was seen in $9 \%$ and $10 \%$ of cases respectively. No twins occurred in this series. The figures for second degree relatives were $14 \%$ and $5 \%$ for tremor; $12 \%$ and $12 \%$ for Parkinsonism. (Table 1).

The occupations of the Parkinson group of subjects did not differ significantly from those of the control group, except that more (59\% to $40 \%$ ) would have been classified within "clerical" jobs. Only $6 \%$ of patients versus $8 \%$ of controls had any significant exposure to industrial toxins.

It is of interest to note that our patients smoked significantly less than the control population. Only $14 \%$ and $12 \%$ of S.G. II and III still do. Similarly, while $33 \%$ of the control population never smoked in their life, 50 and $57 \%$ of our patients were in that category. (Table 2)

Significant and important findings were uncovered in the metabolic histories of these subjects: (Table 3)

a) Prevalence of Familial Grey Hair

Because the tendency to early onset familial grey hair (defined as before age 
TABLE 1

Early Onset Parkinson Details of Familial Cases (expressed in percentages)

\begin{tabular}{|c|c|c|c|c|c|}
\hline & Control & S.G. I & S.G. II & S.G. III & Total \\
\hline 1. Number of Cases & 30 & 11 & 64 & 60 & 135 \\
\hline 2. Tremor Cases & 3 & 9 & 34 & 13 & 23 \\
\hline $\begin{array}{l}\text { a) First degree } \\
\text { relatives }\end{array}$ & 0 & 0 & 20 & 8 & 13 \\
\hline $\begin{array}{l}\text { b) Second degree } \\
\text { relatives }\end{array}$ & 3. & 9 & 14 & 5 & 10 \\
\hline 3. Parkinson Cases & 3 & 36 & 21 & 22 & 23 \\
\hline $\begin{array}{l}\text { a) First degree } \\
\text { relatives }\end{array}$ & 0 & 18 & 9 & 10 & 10 \\
\hline $\begin{array}{l}\text { b) Second degree } \\
\text { relatives }\end{array}$ & 3 & 18 & 12 & 12 & 13 \\
\hline 4. Twins & $\mathbf{0}$ & $\mathbf{0}$ & $\mathbf{0}$ & $\mathbf{0}$ & 0 \\
\hline $\begin{array}{l}\text { 5. Familial Incidence } \\
\text { (total) }\end{array}$ & 3 & 45 & 55 & 35 & 46 \\
\hline
\end{tabular}

TABLE 2

Early Onset Parkinson Prevalence of Smoking

Groups
1. CONTROL
2. PARKINSON (
a) Sub-group I
b) Sub-group II
c) Sub-group III

\begin{tabular}{|c|c|c|c|}
\hline \multicolumn{4}{|c|}{ Percentage (\%) } \\
\hline $\mathbf{N}$ & Never & Yes-Now Stopped & Still \\
\hline 30 & 33 & 17 & 50 \\
\hline 135 & 50 & 36 & 14 \\
\hline 11 & 18 & 54 & 27 \\
\hline 64 & 50 & 36 & 14 \\
\hline 60 & 57 & 32 & 12 \\
\hline
\end{tabular}

TABLE 3

Metabolic Findings in Early Onset Parkinson's Disease (in percentage occurrence)

Group N Familial Hypertension Hypertension Diabetes Diabetes Grey Hair (self) (in family) (self) (in family)

$\begin{array}{lllllll}\text { 1. NORMAL CONTROL } & 30 & 13 & 10 & 33 & 3 & 27\end{array}$

2. TOTAL PARKINSON

$\begin{array}{lrr}\text { GROUP } & 135 & 23 \\ \text { - Sub-group I } & 11 & 18 \\ \text { - Sub-group II } & 64 & 28 \\ \text { - Sub-group III } & 60 & 20\end{array}$

35 ) is seen often in families with macrocytic anemia, we searched for this trait. $13 \%$ of our control group subjects reported this observation, while $23 \%$ of our total group of Parkinsonism did. This was more frequent $(28 \%)$ in those patients with tremor onset.

\section{c) Prevalence of Diabetes}

$27 \%$ of the control group had clinical diabetes (defined as blood glucose levels higher than $120 \mathrm{mg} / 100 \mathrm{ml}$ ). $35 \%$ of the Parkinsonian patients answered to these criteria, with a roughly equivalent distribution within the sub-groups.

\section{d) Prevalence of Thyroidopathy}

A history of hypo or hyper-thyroidism, or of goitre, was obtained in $3 \%$ of the control subjects themselves, and $16 \%$ of the Parkinsonian patients. Similarly $3 \%$ of the mothers and $0 \%$ of the siblings were affected in the control group. $16 \%$ of the mothers and $8 \%$ of the siblings were positive for thyroidopathies, in the Parkinson group. (Table 4) The breakdown of the type of thryoid dysfunction will be seen later.

\section{e) Food Preference}

Subjects were asked what foods they particularly craved, and what foods they detested. It is not surprising that $20 \%$ of control subjects spontaneously listed cravings for "sweets" and 14\% for milk products. The figures for the parkinsonian group as a whole were significantly different only for "sweets" (listed by $51 \%$ of patients). However, we were intrigued by the fact that $24 \%$ of Parkinsonians (versus 3\%) spontaneously stated that they detested green vegetables; $8 \%$ felt similarly towards liver (versus $2 \%$ ). This observation, if confirmed by larger studies, may justify an investigation into certain products found in certain foods that may be adverse to Parkinsonian patients.

\section{f) Trigger Factors}

Finally, we looked into the type of events that the patients spontaneously listed as associated with the onset of their illness. $65 \%$ of patients identified one major event with the possible trigger. Emotional factors accounted for $25 \%$ of cases and, as expected, trauma $(6 \%)$, flu state $(6 \%)$, use of neuroleptics $(6 \%)$, alcoholism (6\%) were equally mentioned. Surprisingly, $16 \%$ of patients noted that the first symptoms followed a strict reducing diet. It is unfortunately not known whether "reducing pills", such as amphetamines, were used. 
TABLE 4

Early Onset Parkinson

Prevalence of Goitre (\%)

Parkinson

$\begin{array}{cccc}\text { Control } & \text { S.G. I } & \text { S.G. II } & \text { S.G. III } \\ 30 & 11 & 64 & 60 \\ 3 & 0 & 17 & 16 \\ & & & \\ 3 & 10 & 13 & \mathbf{1 8} \\ 0 & 0 & 0 & 2 \\ 0 & 0 & 11 & 5 \\ & & & \\ 7 & 0 & 19 & 13 \\ 0 & 10 & 2 & 0\end{array}$

Thus, this preliminary survey of the sub-group of patients with disease onset below the age of 40 , reveals a high familial incidence of tremor and of Parkinsonism (46\%) and indications of high prevalences of familial grey hair, diabetes, hypertension, and thyroidopathy. In order to better analyse and understand these results, we undertook to record the same data according to the presence of a positive family history.

\section{A SURVEY OF THE \\ FAMILIAL CASES}

We selected from the total group, two possibly "genetic" sub-groups:

1. Patients with a positive family history of Parkinson's disease (Subgroup A)

2. Patients with a positive family history of tremor (Sub-group B)

The main characteristics of these sub-groups are:

1. Sub-group A: familial Parkinson (N: 12 index cases; $50 \%$ males; mean age $49.2 \mathrm{yrs}$; mean age of onset 31.2 yrs)

2. Sub-group B: familial tremor (N: 17 index cases; $52 \%$ males; mean age $51.9 \mathrm{yrs}$; mean age of onset 36.0 yrs)

Thus the "familial Parkinson" subgroup (A) starts earlier (by a mean of 5 years) and is more severely affected (25\% versus $12 \%$ in stage 3 of $0-3$ scale) than the "familial tremor" sub- group (B). Their symptomatology also differs:

1. Sub-group A: "Familial Parkinson": $78 \%$ of the patients are mainly akineto-rigid, while $23 \%$ have the full triad. None present now with predominant tremor.

2. Sub-group B: "Familial tremor": $4 \%$ were predominantly akinetorigid at the time of examination, $38 \%$ had the full triad and $58 \%$ had tremor as the main symptom.

It is therefore evident, allowing for a few mis-classified subjects, that we are dealing with two very different entities. The rest of our analysis will bear out this conclusion:

\section{a) Family History}

All of the subjects, by definition, have a positive family history. First degree relatives were distributed almost equally between fathers, mothers and siblings. In fact, there were 14 cases of Parkinson (5 fathers, 4 mothers, 5 siblings) in the 12 index families of subgroup A "Familial Parkinson", with not a single case of simple tremor. In the 17 sub-group B "Familial tremor" families, there were 20 cases of simple tremor ( 9 fathers, 8 mothers and 3 siblings), and none of Parkinsonism.

\section{b) Smoking Habit}

In sub-group A "Familial Parkinson" a striking $67 \%$ of the subjects had never smoked and only $8 \%$ still smoked occasionally. None of the subjects could be counted as a heavy smoker, reinforcing the impression that this group was metabolically different. In sub-group B "Familial tremor" 59\% never smoked, $18 \%$ still were smokers. In the control group $33 \%$ never smoked; $17 \%$ smoked once but had stopped, and $50 \%$ still smoked.

\section{c) Prevalence of Familial Early \\ Grey Hair}

One of the most striking differences can be found for this association. Whereas $13 \%$ of the control group had the familial trait of early onset grey hair, $0 \%$ of sub-group A "Familial Parkinson" and $42 \%$ of sub-group B "Familial tremor" had the trait. It should be also mentioned that the 3 patients with macrocytic anemia fell within the predominantly tremor subgroup II in the first phase of our study. Thus tremor and early onset grey hair appear to be linked somehow.

\section{d) Prevalence of Diabetes}

Diabetes was not significantly different in the sub-groups when the patients themselves were considered $(0 \%(\mathrm{~A})$ to $12 \%(\mathrm{~B}))$, but there was a trend towards a higher prevalence of diabetes in the relatives of sub-group $A$ "Familial Parkinson". The figures were $50 \%$ in $\mathrm{A}, 29 \%$ in $\mathrm{B}$ and $27 \%$ in the control group.

\section{e) Prevalence of Hypertension}

Hypertension was 3 to 4 times more frequent in patients of sub-group $A$ "Familial Parkinson" than in controls or sub-group B "Familial tremor" subjects $(33 \%, 10 \%$ and $6 \%$ respectively). There was no significant difference in hypertension in the relatives of the three groups.

\section{f) Prevalence of Thyroidopathy (Table} 5)

$17 \%$ of sub-group A "Familial Parkinson" patients had suffered from hypothyroidism; the corresponding figures were $3 \%$ for the controls and $0 \%$ for sub-group B "familial tremor". On the other hand, none of the patients in sub-group A had hyperthyroidism, while $27 \%$ of sub-group B were so classified (and 3\% in the control group). The hypothyroidism of sub-group A carries over to their families. Thus $25 \%$ of the siblings are also affected as compared to $0 \%$ for sub-group B and $3 \%$ for the controls. On the other hand, the hyperthyroidism of sub-group $B$ is 
TABLE 5

Familial Cases of Early Onset Parkinson

Prevalence of Thyroidopathy (\%)

\begin{tabular}{|c|c|}
\hline $\begin{array}{l}\text { Control } \\
\text { (n: } 30)\end{array}$ & $\begin{array}{l}\text { Parkinson in Family Tremor in Family } \\
\text { (n: 12) }\end{array}$ \\
\hline
\end{tabular}

A. Self

a) Hypothyroid

b) Hyperthyroid

3

3

B. Siblings

a) Hypothyroid

b) Hyperthyroid

c. Mothers

a) Hypothyroid

b) Hyperthyroid

D. Maternal Relatives

a) Hypothyroid

b) Hyperthyroid

E. Fathers \& Paternal Relatives

a) Hypo \& Hyperthyroid

0

3

0

3

0

7

0

reflected in a similar incidence $(27 \%)$ in their mothers and in maternal relatives (also $27 \%$ of the index cases). The highest figure for the same relatives of sub-group A patients, and of controls, is $6 \%$.

To further evaluate this striking difference, we looked at the biochemical data concerning the thyroid in our own cases of familial Parkinson and familial tremor with Parkinson. Unfortunately, the numbers are too few for statistical analysis, but the trends confirm the clinical observations. Thus total T3 and free T3 were at the upper limits of nor$\mathrm{mal}$ (mean of 174.5 and $0.73 \mathrm{mg} / \mathrm{dl}$ respectively, $N: 8$ ) in sub-group $B$ "Familial tremor", and much lower but probably normal in sub-group A "Familial Parkinson" (mean of 104 and $0.43 \mathrm{mg} / \mathrm{dl}$ respectively; $\mathrm{N}: 2$ ). On the other hand, total T4 and, less so, free T4 were elevated in sub-group A "Familial Parkinson" (mean of 11.90 and 3.2 respectively), but normal (mean of 8.6 and $2.6 \mathrm{mg} / \mathrm{dl}$ respectively) in sub-group $B$. The percentage saturation of TBG was $31.2 \%$ in S.G. A and 28.2 in S.G. B.

\section{DISCUSSION}

The study of early onset Parkinsonism, although admittedly limited by the availability of patients, has been able to answer negatively the initial question: We can now state that the socalled "Idiopathic Parkinsonism" is not

a single clinical entity. To focus our attention and to avoid the usual pitfalls accompanying old age, arteriosclerosis or premature aging, we purposely chose patients whose disease started before the age of 40 . In this selected group of our own patients, the first observation of importance was that the familial incidence of other extrapyramidal symptoms was between $35 \%$ and $55 \%$, a figure much higher than the usual $10 \%-15 \%$ quoted for Parkinson's disease in general (see introduction) but similar to the report of Yokochi \& Narabayashi (1981). The second observation was that these extrapyramidal manifestations in relatives correlated with the type of onset and the natural history of the disease in the index cases: Thus, patients whose disease was initiated and principally manifested with tremor had a higher incidence of cases of essential tremor in their relatives (including 1st degree relatives). On the other hand, patients whose disease started with an akineto-rigid syndrome and remained so, were more severely affected, and had a high incidence of clearly delineated akineto-rigid Parkinsonism in parents and siblings. Almost no cases of pure, or essential tremor are found in their families.

We can now conclude that the usual explanation for coexistence of Parkinson's disease and essential tremor in the same families is probably wrong.
Mjönes (1949) thought that the tremor cases observed among the relatives of a subject with Parkinson's disease (PD) were "formes frustes" of PD. We would like to look at the same association in exactly the opposite way: cases of PD appear more frequently in "essential tremor" families because these patients are genetically more susceptible to whatever triggers the appearance of PD. This explanation would be compatible with the same phenomenon after phenothiazines (Ayd, 1961).

These preliminary observations on the existence of at least two sub-groups of early onset Parkinson's disease (three if post-encephalitic cases are also included) were completed by the recognition of the higher prevalence in these patients of a number of metabolic changes: hypertension, diabetes, familial early grey hair, macrocytic anemia and thyroidopathies.
In order to further refine our findings, it was decided to look at the same data in only the familial cases of early onset PD. To be absolutely sure that we selected most cases of homogeneous genetic patterns, we included only cases of PD who had a first degree relative with extrapyramidal symptoms. No cases of Wilson's disease or Huntington's Chorea (the usual difficult differential diagnosis) were uncovered. Nevertheless, two clearly distinct sub-groups emerged: one with familial incidence of tremor as the main symptom (but with clear-cut PD in the index case, albeit tremor dominant) and the other with familial incidence of Parkinsonism, of the akineto-rigid form. These two genetic sub-groups of Parkinson's disease had clearly distinct metabolic and clinical patterns:

A.The Familial Metabolic AkinetoRigid Syndrome (Sub-group A)

1. With other cases of full blown Parkinson in the family.

2. No sex predominance

3. Relatively more severe disease, but not necessarily a faster course.

4. A high prevalence of diastolic hypertension in the patients and their families.

5. A high susceptibility to DOPA induced hypotension and abnormal involuntary movements. 
6. A high prevalence of hypothyroidism in patients and siblings at one stage of their lives.

7. A high prevalence of diabetes in their families.

8. Apparently more intellectual dysfunction

B. The "Essential Tremor-Related" Parkinsonism Syndrome (Sub-group B)

1. With numerous cases of "essential" tremor in the immediate family

2. Apparent dominant inheritance of the essential tremor within the families.

3. Preponderance of male cases of Parkinsonism.

4. Possible existence of maternal modifying factors.

5. A high prevalence of familial early-onset grey hair.

6. A high prevalence of hyperthyroidism in patients, mothers and maternal relatives.

Admittedly our own cases, and those collated from the mail survey, although they correspond to this sub-division, must suffer from a certain degree of imprecision and overlap. This is the usual fate of retrospective studies. We have now undertaken a systematic prospective study of these and new cases, in the hope of clarifying even better the genetic classification of these sub-groups. We are sufficiently confident in their existence, however, to now propose a new classification of Parkinson's disease (Table 6).

This new classification permits the distinction of 5 new sub-groups which should be useful for prospective biochemical studies (now undertaken in our laboratory). Thus within the "Idiopathic Parkinson's disease" clas-

sification of old, we can now isolate a few genetic sub-groups, leaving a vast majority of subjects who can only be differentiated by their mode of onset (tremor versus akineto-rigid). Some of these, undoubtedly, belong to the genetic sub-groups, but cannot yet be properly assigned to them. To maintain the homogeneity of these genetic subgroups, and until genetic markers have been identified, we propose that only cases with affected first degree relatives be assigned to these sub-groups. It is probable that for most of the other "Idiopathic" cases, there is at least a genetic susceptibility factor at work.

One last word should be addressed to the extraordinary presence of thyroidopathies in these patients. Associations between Parkinson's disease and hyperthyroid goitre have been known for a long time and have interested many neurologists (Bartels and Bohart, 1958) and will be reviewed by us elsewhere. It is also of interest that the removal of a hyperthyroid goitre has been followed many years later by the development of the classic features of Parkinsonism, often with concomitant hypoparathyroidism (Clarke and Frame, 1962). Sometimes, this picture is reversible after the repletion of serum calcium (Berger and Ross, 1981); We had previously shown (Barbeau and Raymond Tremblay, 1965) that Parkinsonian patients do not react normally to the classical Howard test of parathyroid function. It would thus seem that thyroid function (hypo or hyper?) could be abnormal in these patients and serve as a trigger to the eventual development of Parkinson's disease in genetically susceptible individuals, directly, through effects on the dopamine receptors, or indirectly through deranged parathyroid meta-

TABLE 6

Proposed Functional Classification of Parkinson's disease

TYPE I

TYPE II

$\begin{array}{lll} & \text { IIa } & \\ & \text { IIb } & : \text { Tremor Onset Form } \\ & : \text { Akineto-Rigid Onset Form } \\ & : \text { Genetic } \\ \text { TYPE III } & & : \text { Familial Metabolic Akineto-Rigid Syndrome } \\ & \text { IIIa } & \text { Familial "Essential-Tremor-Related" } \\ \text { Parkinsonism } \\ : \text { Familial Juvenile Parkinsonism } \\ \text { IIIb } & \text { Symptomatic }\end{array}$

bolism. This whole new field is totally unexplored but should, with the use of modern techniques now available, be worth a detailed study. Finally, the higher incidence of hypothyroidism in at least one form of Parkinson's disease that we describe in the present survey is supported by a recent observation of Burger and Kelley (1981). We also confirm, in a preliminary way, the report of Nowack (1980) that seems to implicate T3 hyperfunction in some patients with Parkinson's disease (in our series this would be Familial SubGroup B) and T4 hyperfunction in others.

\section{ACKNOWLEDGEMENTS}

The studies reported in this paper were supported by the United Parkinson Foundation, The Rice Foundation, La Fondation Parkinson du Québec and the Medical Research Council of Canada (MA-4938). We particularly thank the individuals and physicians who, through their correspondence, made this survey possible. A preliminary summary version of this paper is being published in the Proceedings of the 12th World Congress of Neurology, by Excerpta Medica.

\section{REFERENCES}

AYD, F.J. (1961). A survey of drug-induced extrapyramidal reactions. J. Am Med. Ass. 197: $1054-1069$

BARBEAU, A. and JOLY, J.G. (1963). Parkinson et cancer. Union médicale du Canada 92: 169.174

BARBEAU, A. and RAYMOND-TREMBLAY, W. (1965). Recent biochemical studies in Parkinson's Disease and position of the problem. In: Parkinson's Disease Trends in Research and Treatment. (ed. A. Barbeau, L. Doshay and E.A. Spiegel) Grune \& Stratton, pp. 79-94

BARTELS, E.C. and ROHART, R.R. (1958). The Relationship of Hyperthyroidism and Parkinsonism. AMA Arch. Int. Med. 101: 562-568

BAUMANN, R.J.; JAMESON, H.D.; McKEAN, H.E.; HAACK, D.G. and WEISBERG, L.M. (1980). Cigarette smoking and Parkinson's Disease: 1. A comparison of cases with matched neighbors. Neurology (NY) 30: 839-843

BERGER, J.R. and KELLEY, R.E. (198!) Thyroid function in Parkinson Disease. Neurology (NY) 31: 93-95

BERGER, J.R. and ROSS, D.B. (1981). Reversible Parkinson syndrome complicating postoperative hypoparathyroidism. Neuro$\log y(N Y)$ 31: $881-882$

BIRMAYER, W., REIDERER, P. and YOUDIM, J.B.H. (1979). Distinction between benign and malignant type of Parkinson's Disease. Clin. Neurol. Neurosurg. $81: 158-164$ 
CLARKE, H.A. and FRAME, B. (1962). Parkinson's Disease associated with hypothyroidism. Henry Ford Hospital Med. Bull. 10: 51-53

DUVOISIN, R.C., GEARING, F.R.; SCHWEITZER, M.D., and YAHR, M.D. (1969). A family study of Parkinsonism. In: Progress in neuro-genetics (Ed. A. Barbeau and J.R. Brunette) Excerpta Medica Foundation, Amsterdam pp. $492-496$

KESSLER, I.I. (1978). "Parkinson's Disease in Epidemiologic Perspective". Advances in Neurology 19: 355-384

KONDO, K., JURLAND, L.T. and SCHULL, WJ. (1973). Parkinson's Disease. Genetic Analysis and Evidence of a Multifactorial Etiology. Mayo Clinic Proc 48: 465-475
MARTIN, W.E., RESCH, J.A. and BAKER, A.B. (1971). Juvenile Parkinsonism. Arch. Neurol. 25: 494-500

MARTIN, W.E., YOUNG, W.I. and ANDERSON, V.E. (1973). Parkinson's Disease - A genetic Study. Brain 96: 495-506

MJÖNES, H. (1949). Paralysis agitans: A clinical and genetic study. Acta Psychiat. Scand., Suppl. 54, p. 1. Munksgaard, Copenhagen.

MORTIMER, J.A., PIROZZOLO, F.J., HANSCH, E.C. and WEBSTER, D.A. (1981). Relation of motor symptoms to intellectual deficits in Parkinson's Disease. Neurology (NY) 31: 61

MYRIANTHOPOULOS, N.C., WALDROP, F.N. and VINCENT, B.L. (1969). A repeat study of hereditary predisposition in drug- induced Parkinsonism. In: Progress in Neuro-genetics (Ed. A. Barbeau and J.R. Brunette) Excerpta Medica Foundation, Amsterdam. pp. 486-491

NOWACK, W.J. (1980). Hyperthyroidism, Parkinsonism and Tri-iodo thyronine receptors. Soc. Neurosciences Abst. 6: 803

WARD, C.D., DUVOISIN, R.C., INCE, S.E., NUTT, J.D., ELDRIDGE, R. and CALNE, D.B. (1981). Parkinson's Disease in twins and in a set of quadruplets. Neurology (NY) $31: 110$

YOKOCHI, M. and NARABAYASHI, $\mathrm{H}$. (1981). Clinical characteristics in juvenile Parkinsonism. In: Research Progress in Parkinson's Disease. (F. Clifford Rose and R. Capildeo, Eds). Pitman Medical, Turnbridge Wells, pp 35-39. 